\title{
PRE AND POSTMENOPAUSAL CHANGES OF BONE MINERAL DENSITY: A COMPARATIVE STUDY DONE BY DUAL ENERGY X-RAY ABSORPTIOMETRY
}

\author{
M BEGUM ${ }^{1}$, MI PATWARY ${ }^{2}$, MA AHBAB $^{3}, \mathrm{MH} \mathrm{KHAN}^{4}, \mathrm{AI} \mathrm{CHOWDHURY}^{5}, \mathrm{~F}_{\mathrm{BARI}}{ }^{6}$
}

\begin{abstract}
:
Background: Accelerated decline of bone mass occurs in women after the menopause, and might lead to excessive bone resorption and eventually to osteoporosis. ${ }^{1}$ To find out the changes of bone mineral density (BMD) before and after menopause, the shown was undertaken.

Materials and Methods: This comparative study was conducted in the Department of Medicine, Sylhet M A G Osmani Medical College Hospital, Sylhet during July 2008 to June 2009. Forty postmenopausal women; monthly income and BMI matched 40 premenopausal women were selected according to inclusion and exclusion criteria. BMD of lumber vertebrae and femoral neck was determined using Dual energy x-ray absorptiometry (DXA) method (Norland XR 46, Pencil beam).

Results: The parity of the postmenopausal women was significantly higher than that of premenopausal women $(6.9 \pm 2.6$ vs $3.1 \pm 1.5 ; p<0.01)$. The body weight was significantly lower in postmenopausal women than that of premenopausal women $(54.1 \pm 8.3 \mathrm{~kg}$ vs $61.0 \pm 9.7 \mathrm{Kg}$; $p<0.01)$. The height was significantly lower in postmenopausal women than premenopausal women $(148.2 \pm 5.7 \mathrm{~cm}$ vs $153.4 \pm 6.4 \mathrm{~cm} ; p<0.01)$. The BMD was lower in postmenopausal women than premenopausal women in lumber vertebrae $\left(0.68 \pm 0.13 \mathrm{gm} / \mathrm{cm}^{2}\right.$ vs $\left.0.94 \pm 0.03 \mathrm{gm} / \mathrm{cm}^{2} ; p<0.01\right)$ and also in femoral neck $\left(0.63 \pm 0.12 \mathrm{gm} / \mathrm{cm}^{2}\right.$ vs $\left.0.84 \pm 0.14 \mathrm{gm} / \mathrm{cm}^{2} ; p<0.01\right)$. A significant positive correlation was present between BMD and height ( $r=0.512 ; p<0.05)$; and weight $(r=0.489$; $p<0.05)$; and a negative correlation between BMD and age ( $r=-0.408 ; p<0.05)$; parity $(r=-0.456$; $p<0.05)$ and years since menopause ( $r=-0.350 ; p<0.05)$.

Conclusion: The BMD was significantly lower in postmenopausal women than that of premenopausal women and negative correlation was present between BMD and age, parity and years since menopause.
\end{abstract}

Keywords: Menopause, Bone mineral density.

\section{Introduction:}

Over the past 10 years, osteoporosis has emerged as a major clinical challenge for physician and patients, with regard both to its prevalence and to the morbidity and mortality of associated fracture. ${ }^{2}$

Osteoporosis affects an estimated 75 million people in Europe, United States of America (USA), and Japan. ${ }^{3}$ Osteoporotic fractures occurs 1 in 3 women as well as 1 in 5 men over 50 years of age. ${ }^{4-6}$

The most important risk factor for bone loss in women is the menopause; Women loss about $50 \%$ of their trabecular bone and 30\% of their cortical bone during the course of their lifetime, about half of which is lost during the first 10years after the menopause. 7,8

A $10 \%$ loss of bone mass can double the risk of vertebral fractures, and 2.5 times greater risk of hip fracture. ${ }^{9}$ Their impact on quality of life can be profound as a result of loss of self-esteem, distorted body image, depression and activities of daily living. ${ }^{10-14}$

In an Indian study among women aged 30-60 years and low income groups showed the bone mineral

1. Assistant Professor of Medicine, Jalalabad Ragib Rabeya Medical College, Sylhet.

2. Head of the Department of Medicine, Sylhet M A G Osmani Medical College, Sylhet.

3. Ex. Principal \& Head of the dept. of Medicine, Sylhet M A G Osmani Medical College, Sylhet

4. Director Nuclear Medicine Centre, Sylhet.

5. Lecturer, Microbiology, Sylhet M A G Osmani Medical College, Sylhet.

6. Registrar, Medicine, Jalalabad Ragib Rabeya Medical College, Sylhet.

Bangladesh J Medicine 2011; $22: 1-7$ 
density (BMD) at all the skeletal sites were much lower than that of developed countries. ${ }^{15}$

Bone mineral density in postmenopausal women was significantly lower than pre-menopausal women in a Bangladeshi study using a bone densitometer Single photon X-ray absorptiometry (SXA). ${ }^{16}$

Evidence suggests that many women who sustain a fragility fracture are not appropriately diagnosed and treated for probable osteoporosis. 17,18

This study had been conducted to find out the changes of BMD before and after menopause with a view to detection of low BMD at an early stage gives an opportunity to intervene timely and will decrease the health hazard associated with it.

\section{Material and Methods:}

This cross-sectional comparative study was carried out among the patients attending in the Department of Medicine, Sylhet M A G Osmani Medical College Hospital and Centre for Nuclear Medicine and Ultrasound, Sylhet during the period from $1^{\text {st }}$ July 2008 to $30^{\text {th }}$ June 2009 with a view to find out the changes of BMD before and after menopause. For this purpose 40 participants aged between 51 to 70 years with body mass index between $>18.5 \mathrm{~kg} / \mathrm{m}^{2}$ to $\mathrm{d}$ " 30 $\mathrm{kg} / \mathrm{m}^{2}$ and non-smoker were included as case (Postmenopausal) and $40 \mathrm{BMI}$ and socioeconomic status matched premenopausal women aged between 31-50 years were taken as control (premenopausal). Consecutive and convenient samples were collected. Secondary causes of decreased bone mineral density were excluded. Primary outcome variable was level of bone mineral density and secondary variables age, parity, height, weight and years since menopause.

Detailed history of women including age, parity, socioeconomic status, education, smoking was taken. Detailed menstrual history of the women were taken considering age of menarche, age of menopause, duration since menopause, type of menopause (natural or surgical) Women were enquired about any history of low back pain, height loss, recurrent fall, immobilization, any disease that known to affect bone metabolism at present or in past. Detailed history of medications was noted. Measurement of height (in meter), weight (in $\mathrm{kg}$ ) and BMI $\left(\mathrm{kg} / \mathrm{m}^{2}\right)$ were done in each patient. Systemic examination was done routinely. BMD was measured using DXA(Norland XR 46, Pencil beam) .

\section{Statistical analysis}

Data was processed and analyzed with the help of Statistical Package for Social Science (SPSS) software version 12. Mean and standard deviation were calculated for continuous data and percentage for categorical data. Unpaired t-test was done for comparison of continuous variable and Chi-square $\left(\chi^{2}\right)$ test for comparison of categorical variable to see the significance of difference. Relationship of variables was seen by multiple logistic regression analysis. $\mathrm{P}$ value $<0.05$ will be taken as significant.

\section{Ethical issues}

The institutional ethical committee of Sylhet M A G Osmani Medical College, Sylhet approved the study protocol before commencement of the study. Informed written consent of each participant was taken before enrollment.

\section{Results}

The mean parity was $6.88 \pm 2.58$ in the postmenopausal group and $3.10 \pm 1.48$ in the premenopausal (control) group $(\mathrm{p}<0.01)$ (table-I).

In the postmenopausal group, 22 (55.0\%) were illiterate, 12 (30.0\%) had primary level, 4 (10.0\%) had secondary level, 1 (2.5\%) had higher secondary level and $1(2.5 \%)$ had graduation or above in their education level; where as in the premenopausal group, 20 (50.0\%) were illiterate, 10 (25.0\%) had primary level, 4 (10.0\%) had secondary level, 4 (10.0\%) had higher secondary level and 2 (5.0\%) had graduation or above in their education level $(\mathrm{p}=0.325)$ (table-I).

Eighteen (45.0\%) had monthly income of less than 5000.00 taka, 12 (30.0\%) had monthly income of 5000.00 to 7000.00 taka and $10(25.0 \%)$ had monthly income of more than 7000.00 taka in the postmenopausal group; where as in the premenopausal group, 15 (37.5\%) patients had monthly income of less than 5000.00 taka, 13 (32.5\%) had monthly income of 5000.00 to 7000.00 taka and $12(30.0 \%)$ had monthly income of more than 7000.00 taka $(\mathrm{p}=0.875)$; indicating the study was monthly income matched (table-I).

In the postmenopausal group, the mean height of the patients was $148.15 \pm 5.69 \mathrm{~cm}$; whereas the mean height of the premenopausal group was $153.35 \pm 6.43$ $\mathrm{cm}(\mathrm{p}<0.01)$ (table-I).

The mean body weight of the postmenopausal group was $54.05 \pm 8.31 \mathrm{Kg}$; where as the mean body weight of the premenopausal group was $61.03 \pm 9.74 \mathrm{Kg}$ $(\mathrm{p}=0.01)$ (table-I).

The mean BMI was $23.88 \pm 3.35 \mathrm{Kg} / \mathrm{m}^{2}$ in the postmenopausal group and $25.28 \pm 3.27 \mathrm{Kg} / \mathrm{m}^{2}$ in the premenopausal group $(\mathrm{p}>0.05)$; suggesting BMI matched study (table-I). 
Table-I

Distribution of the patients by baseline characteristics

\begin{tabular}{|c|c|c|c|}
\hline $\begin{array}{l}\text { Baseline } \\
\text { characteristics }\end{array}$ & $\begin{array}{c}\text { Postmenopausal } \\
\text { group }(\mathrm{n}=40)\end{array}$ & $\begin{array}{l}\text { Premenopausal } \\
\text { group }(\mathrm{n}=40)\end{array}$ & $\begin{array}{c}\mathrm{p} \\
\text { value }\end{array}$ \\
\hline $\begin{array}{l}\text { Parity } \\
\text { (mean } \pm \mathrm{SD})\end{array}$ & $\begin{array}{c}6.875 \pm 2.580 \\
\text { (range } 2 \text { to } 12 \text { ) }\end{array}$ & $\begin{array}{l}3.100 \pm 2.580 \\
\text { (range } 0 \text { to } 7 \text { ) }\end{array}$ & $<0.01^{*}$ \\
\hline \multicolumn{4}{|l|}{ Education } \\
\hline Illiterate & $22(55.0)$ & $20(50.0)$ & $0.325^{\dagger}$ \\
\hline Primary & $12(30.0)$ & $10(25.0)$ & \\
\hline Secondary & $4(10.0)$ & $4(10.0)$ & \\
\hline Higher secondary & $1(2.5)$ & $4(10.0)$ & \\
\hline e" Graduate & $1(2.5)$ & $2(5.0)$ & \\
\hline \multicolumn{4}{|c|}{ Monthly income (in taka) } \\
\hline$<5000$ & $18(45.0 \%)$ & $15(37.5 \%)$ & $0.875^{\dagger}$ \\
\hline $5000-7000$ & $12(30 \%)$ & $13(32.5 \%)$ & \\
\hline$>7000$ & $10(25.0 \%)$ & $12(30.0 \%)$ & \\
\hline Height (mean \pm & $148.15 \pm 5.69$ & $153.35 \pm 6.43$ & $<0.01^{*}$ \\
\hline $\mathrm{SD})$ & (range 140 to 160 ) & (range 139 to 165 ) & \\
\hline $\begin{array}{l}\text { Weight (mean } \pm \\
\text { SD) }\end{array}$ & $\begin{array}{l}54.05 \pm 8.31 \\
\text { (range } 40 \text { to } 72 \text { ) }\end{array}$ & $\begin{array}{c}61.03 \pm 9.74 \\
\text { (range } 40 \text { to } 80 \text { ) }\end{array}$ & $<0.01^{*}$ \\
\hline $\begin{array}{l}\text { BMI } \\
\text { (mean } \pm \mathrm{SD})\end{array}$ & $\begin{array}{l}23.88 \pm 3.35 \\
\text { (range } 19 \text { to } 29 \text { ) }\end{array}$ & $\begin{array}{c}25.28 \pm 3.27 \\
\text { (range } 20 \text { to } 29 \text { ) }\end{array}$ & $>0.05^{*}$ \\
\hline
\end{tabular}

*Unpaired t-test and ${ }^{\dagger} \mathrm{c}^{2}$ Chi-Squre test were applied to analyse the data.

$\mathrm{n}=$ total number.

$\mathrm{SD}=$ Standard deviation .

BMD in lumber vertebrae was nearly stable in premenopausal women (31-50 years), but decreased sharply in postmenopausal women. Distribution of BMD in lumber vertebrae in different age group was shown in figure-1.
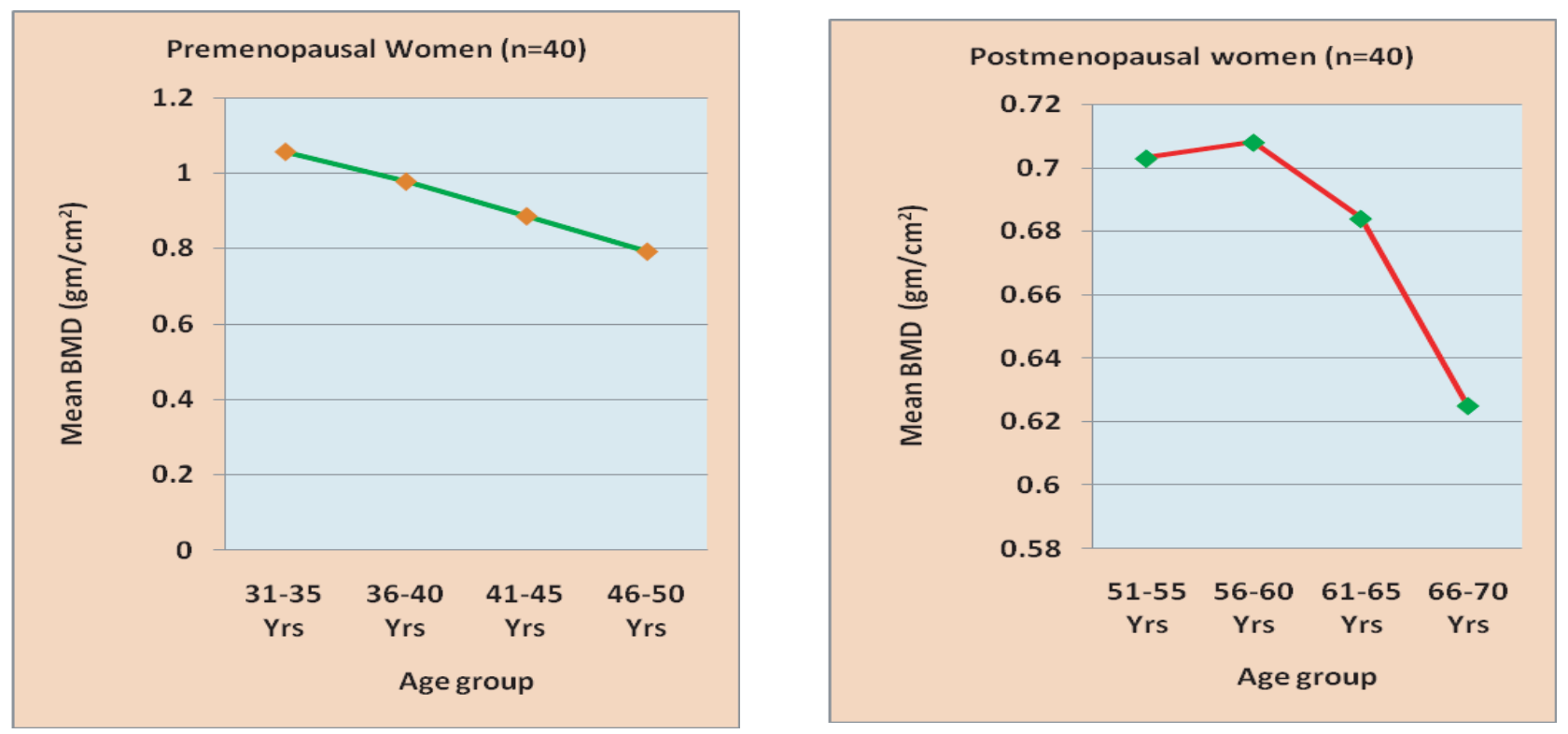

Fig.-1: Distribution of BMD in lumber vertebrae in different age group 
BMD in femoral neck was nearly stable in premenopausal women (31-50 years), but decreased sharply in postmenopausal women. Distribution of BMD in femoral neck in different age group was shown in figure-2.
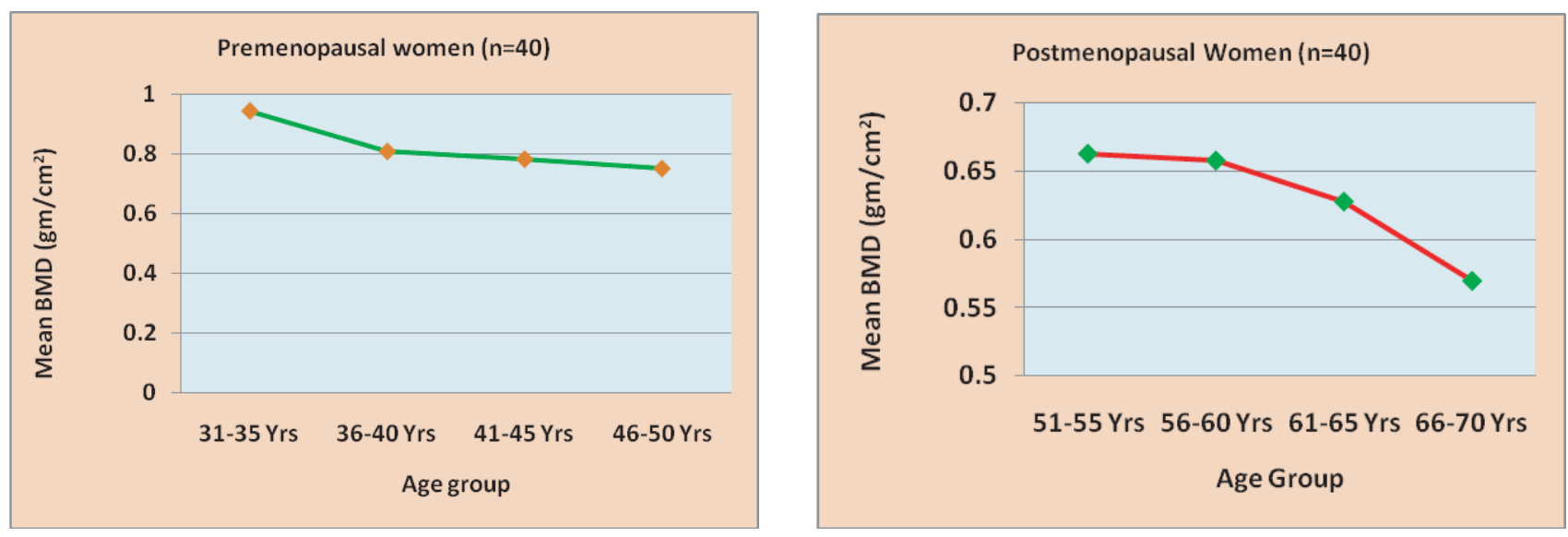

Fig.-2: Distribution of BMD in femoral neck in different age group

In the postmenopausal group, the mean BMD in lumber vertebrae was $0.68 \pm 0.13 \mathrm{gm} / \mathrm{cm}^{2}$; whereas the mean BMD in lumber vertebra was $0.94 \pm 0.03 \mathrm{gm} /$ $\mathrm{cm}^{2}$ in the premenopausal group ( $\left.<<0.01\right)$ (table-II).

The mean BMD in femoral neck was $0.63 \pm 0.12 \mathrm{gm} /$ $\mathrm{cm}^{2}$ in the postmenopausal group; whereas the mean BMD in femoral neck was $0.84 \pm 0.14 \mathrm{gm} / \mathrm{cm}^{2}$ in the premenopausal group ( $\mathrm{p}<0.01$ ) (table-II).
Data were presented as mean $\pm \mathrm{SD}$. Comparison was done between groups by * unpaired t test.

In the postmenopausal group, BMD was osteoporotic level in $21(52.5 \%)$, osteopenic level in $8(20.0 \%)$ patients, combined in $9(22.5 \%)$ and normal level in 2 (5.0\%) patients; where as in the premenopausal group, osteoporotic level was in 5 (12.5\%), osteopenic level in 17 (42.5\%), combined in 2(5.0\%) and normal level in $16(40.0 \%)$ patients $(\mathrm{p}<0.001)$ (table-III).

Table-II

Distribution of the patients by BMD

\begin{tabular}{lccc}
\hline $\begin{array}{l}\text { BMD } \\
\left(\mathrm{gm} / \mathrm{cm}^{2}\right)\end{array}$ & $\begin{array}{c}\text { Postmenopausal } \\
\text { group }(\mathrm{n}=40)\end{array}$ & $\begin{array}{c}\text { Premenopausal group } \\
(\mathrm{n}=40)\end{array}$ & $\begin{array}{c}{ }^{*} \mathrm{p} \\
\text { value }\end{array}$ \\
\hline Lumber & $0.68 \pm 0.13$ (range & $0.94 \pm 0.03$ & $<0.01$ \\
vertebra & 0.42 to 1.02$)$ & (range 0.51 to 1.27) & $<0.01$ \\
Femoral neck & $0.63 \pm 0.12$ (range & $0.84 \pm 0.14$ & \\
& 0.45 to 0.91$)$ & (range 0.47 to 1.02) & \\
\hline
\end{tabular}

Table-III

Distribution of patients by BMD (Based on WHO Criteria)

\begin{tabular}{lccc}
\hline BMD & \multicolumn{2}{c}{ Study group } & ${ }^{*}$ value \\
& $\begin{array}{c}\text { Postmenopausal } \\
\text { women }(\mathrm{n}=40)\end{array}$ & $\begin{array}{c}\text { Premenopausal } \\
\text { women }(\mathrm{n}=40)\end{array}$ & $<0.001$ \\
Normal & $2(5.0)$ & $16(40.0)$ & $17(42.5)$ \\
Osteopenia & $8(20.0)$ & $5(12.5)$ \\
Combined & $21(52.5)$ & $2(5.0)$ \\
\hline
\end{tabular}

* WHO criteria (by T-score)

Normal: T-score of -1.0 or above

Osteopenia: T-score of -1.1 to 2.4

Osteoporosis: T-score of -2.5 or below
* Combined (either osteoporosis of LV and osteopenia of FN or osteoporosis of FN and osteopenia of LV).

* $\chi^{2}$ Chi-square test was applied to analyse the data. 
Table-IV

Correlation of bone mineral density and selected variables -

\begin{tabular}{lcccccc}
\hline Variables & BMD & Age & Parity & Menopause & Height & Weight \\
\hline BMD & 1.000 & $-0.408^{*}$ & $-0.456^{*}$ & $0.350^{*}$ & $0.512^{* *}$ & $0.489^{*}$ \\
Age & $0.408^{*}$ & 1.000 & $-0.998^{* *}$ & $0.988^{* *}$ & $0.992^{* *}$ & $0.990^{* *}$ \\
Parity & $0.456^{*}$ & $-0.998^{* *}$ & 1.000 & 0.985 & 0.996 & $0.994^{* *}$ \\
Menopause & $0.350^{*}$ & $0.988^{* *}$ & 0.985 & 1.000 & $-0.972^{* *}$ & $-0.969^{* *}$ \\
Height & $0.512^{*}$ & $0.992^{* *}$ & 0.996 & $-0.972^{* *}$ & 1.000 & $-0.989^{* *}$ \\
Weight & $0.489^{*}$ & $0.990^{* *}$ & $0.994^{* *}$ & $-0.969^{* *}$ & $-0.989^{* *}$ & 1.000 \\
\hline
\end{tabular}

Regarding correlation between BMD and selected variables showed that a significantly negative correlation was present between BMD and age $(\mathrm{r}=-$ $0.408 ; \mathrm{p}<0.05)$, parity $(\mathrm{r}=-0.456 ; \mathrm{p}<0.05)$, years since menopause $(\mathrm{r}=-0.350 ; \mathrm{p}<0.05)$. But a significantly positive correlation was present between BMD and height $(\mathrm{r}=0.512 ; \mathrm{p}<0.01)$, weight $(\mathrm{r}=0.489 ; \mathrm{p}<0.05)$ (table-IV).

\section{Discussion}

Osteoporosis and low bone marrow density are significant risk factors for morbidity and mortality in older adults. Not only it gives rise to morbidity but also markedly diminishes the quality of life of women after menopause. ${ }^{19}$

The parity of the postmenopausal women was significantly greater than the premenopausal women $(6.88 \pm 2.58$ vs $3.10 \pm 1.48 ; \mathrm{p}<0.01)$. Similar finding was observed in the study of Chowdhury. ${ }^{6}$ Premenopausal women have got chance of having children in future which may cause this disparity. In the present study a significantly negative correlation was present between BMD and parity $(r=-0.456$; $\mathrm{p}<0.05)$. This result was correlated with the study conducted by Chowdhury ${ }^{16}$

In postmenopausal group $55.0 \%$ patients were illiterate, $30.0 \%$ had primary leve1, $10.0 \%$ had secondary level; and higher secondary level and graduation or above constituted $2.5 \%$ each. In this regards Gur et al, ${ }^{20}$ found that prevalence of osteoporosis had an inverse relationship with the level of education, $18.6 \%$ for the most educated to $34.4 \%$ for the no educated women.

The height of the patients was significantly lower in postmenopausal group than that of premenopausal group $(148.15 \pm 5.69$ vs $153.35 \pm 6.43 ; p<0.01)$ in this study, that also reported by Lau et al, ${ }^{21}(149.3 \pm 6.4$ $\mathrm{cm}$ vs $153.5 \pm 5.7 \mathrm{~cm} ; \mathrm{p}<0.001)$ in their study. a significant positive correlation was found between height and the Bone mineral density $(r=0.512 ; \mathrm{p}<0.05)$ that was similar to the study of Douchi ${ }^{22}$.
The weight was significantly lower in postmenopausal group than that of premenopausal group (54.05 \pm $8.31 \mathrm{~kg}$ vs $61.03 \pm 9.74 \mathrm{Kg} ; \mathrm{p}=0.001)$. This result was supported by Lau et al, ${ }^{21} 53.8 \pm 10.9 \mathrm{~kg}$ vs $56.0 \pm 9.0$ $\mathrm{kg} ; \mathrm{p}<0.01$ ). Chowdhury and his group, ${ }^{16}$ found the mean body weight was $48.2 \pm 10.8 \mathrm{Kg}$ in their postmenopausal women and $49.9 \pm 9.4$ years in premenopausal women; but the difference between the groups was not significant $(p=0.23)$.

Bone mineral density had a positive correlation with body-weight $(\mathrm{r}=0.489 ; \mathrm{p}<0.05)$ in the current study. This result was similar to the study of Chowdhury, ${ }^{16}$ that bone mineral density had a positive correlation with body-weight $(\mathrm{p}<0.05)$.

The mean BMI was $23.88 \pm 3.35 \mathrm{Kg} / \mathrm{m}^{2}$ in the postmenopausal women and $25.28 \pm 3.27 \mathrm{Kg} / \mathrm{m}^{2}$ in premenopausal women. The BMI of the patients in both groups were almost similar statistically $(\mathrm{p}>0.05)$. No significant difference was found between postmenopausal and premenopausal women regarding BMI reported by Chowdhury $(p=0.79) .{ }^{16}$

The bone mineral density in lumber vertebrae was $0.68 \pm 0.13$ in postmenopausal women and $0.94 \pm$ 0.03 in the premenopausal women $(\mathrm{p}<0.01)$. This finding was correlated with Lau et al, ${ }^{21}$ that the bone mineral density in lumber vertebrae was $0.70 \pm 0.16$ in postmenopausal women and $0.96 \pm 0.12$ in the premenopausal women.

The bone mineral density was $0.63 \pm 0.12$ in postmenopausal women, and $0.84 \pm 0.14$ in the premenopausal women in the femoral neck $(\mathrm{p}<0.01)$. This result was also supported by Lau et al that the bone mineral density was $0.55 \pm 0.12$ in postmenopausal women, and $0.80 \pm 0.10$ in the premenopausal women in the femoral neck.

A significant negative correlation was found between BMD and age $(r=-0.408 ; p<0.05$ and this finding was correlated with the study of Chowdhury 16 that a significant negative correlation was present between BMD and age $(\mathrm{p}<0.001)$. 
A significant negative correlation was found between BMD and years since menopause ( $\mathrm{r}=-0.350 ; \mathrm{p}<0.05)$. This result was supported by the study of Douchi, ${ }^{22}$ and Enchev. ${ }^{23}$ A strong negative correlation was found between bone mineral density and years since menopause $(\mathrm{p}<0.001)$ in the study of Douchi, ${ }^{22}$ and a weak negative correlation found between bone mineral density and years since menopause in the study of Enchev et al. ${ }^{23}$

In the present study bone mineral density was osteoporotic level in $21(52.5 \%)$ patients, osteopenic level was in $8(20.0 \%)$ patients, combined in $9(22.5 \%)$ and normal level in $2(5.0 \%)$ patients in the postmenopausal women; whereas in premenopausal group, osteoporotic level was in $5(12.5 \%)$ patients, osteopenic level was in 17 (42.5\%) patients, combined in $2(5.0 \%)$ and normal level was in $16(40.0 \%)$ patients. The level of bone mineral density between the groups was statistically significant $(\mathrm{p}<0.001)$. In this regards Keramat et al, ${ }^{24}$ reported that the prevalence of lumber spine osteoporosis and osteopenia in the postmenopausal women was $26.5 \%$ and $50 \%$ respectively.

In conclusion, the bone mineral density was significantly lower in postmenopausal women than premenopausal women both in lumber and femoral neck; and negative correlation was present between bone mineral density and age, parity and years since menopause.

\section{Recommendation:}

Considering the findings of this study the following recommendations are made:

- A study should be conducted using large sample size in the community level to find out the magnitude of the condition in general population.

- A study involving multicentre with random sampling should be conducted to determine any disparity of bone mineral density through out the country.

\section{Acknowledgement:}

This study was done in as a part of thesis in partial fulfillment of the requirement for Internal Medicine MD Part III examination in Sylhet MAG Osmani Medical College Hospital, Sylhet, Bangladesh.

My heartiest gratitude and thankfulness to all my undergraduate and post graduate teachers.

\section{References:}

1. Sayegh RA, Stubblefield PG. Bone metabolism and the perimenopause: overview, risk factors, screening, and osteoporosis preventive measures. Obstet Gynecol Clin North Am. 2002;29:495-510.
2. Delmas PD, Fraser M. Strong bones in later life: luxury or necessity? Bull World Health Organ. 1994;77:416-22.

3. EFFO, NOF. Who are candidates for prevention and treatment for osteoporosis? Osteoporos Int. 1997; $7: 1$.

4. Melton LJ 3rd, Atkinson EJ, O'Connor MK. Bone density and fracture risk in men. J Bone Miner Res. 1998;13:1915.

5. Melton LJ 3rd, Chrischilles EA, Cooper C. Perspective. How many women have osteoporosis? J Bone Miner Res. 1992;7:1005.

6. Kanis JA, Johnell O, Oden A. Long-term risk of osteoporotic fracture in Malmo. Osteoporos Int. 2000;11:669.

7. Finkelstein JS. Osteoporosis. In: Goldman L, Ausiello D, editors. Cecil textbook of medicine. 22nd ed. Philadelphia: WB Saunders. p. 1547-55.

8. Riggs BL, Melton LJ III. The prevention and treatment of osteoporosis. N Engl J Med. 1992;27:620-7.

9. Klotzbuecher CM, Ross PD, Landsman PB. Patients with prior fractures have an increased risk of future fractures: a summary of the literature and statistical synthesis. J Bone Miner Res. 2000;15:721.

10. Gold DT. The nonskeletal consequences of osteoporotic fractures. Psychologic and social outcomes. Rheum Dis Clin North Am. 2001;27:255.

11. Robbins J, Hirsch C, Whitmer R. The association of bone mineral density and depression in an older population. J Am Geriatr Soc. 2001;49:732.

12. Lyles KW. Osteoporosis and depression: shedding more light upon a complex relationship. J Am Geriatr Soc. 2001;49:827.

13. Tosteson AN, Gabriel SE, Grove MR. Impact of hip and vertebral fractures on quality-adjusted life years. Osteoporos Int. 2001;12:1042.

14. Hall SE, Criddle RA, Comito TL, Prince RL. A casecontrol study of quality of life and functional impairment in women with long-standing vertebral osteoporotic fracture. Osteoporos Int. 1999;9:508.

15. Shatrugna V, Kulkarni B, Kumar PA. Bone status of Indian women from a low-income group and its relationship to the nutritional status. Osteoporos Int. $2005 ; 16: 1827$.

16. Chowdury S, Ashrafunnessa, Khatun S, Sarkar NR. Comparison of BMD between pre-menopausal and post-menopausal women in Bangladesh. Bangladesh Med Res Counc Bull. 2001;27(2):48-54.

17. Freedman KB, Kaplan FS, Bilker WB. Treatment of osteoporosis: are physicians missing an opportunity? J Bone Joint Surg Am. 2000;82-A:1063. 
18. Siris ES, Miller PD, Barrett-Connor E. Identification and fracture outcomes of undiagnosed low bone mineral density in postmenopausal women: results from the National Osteoporosis Risk Assessment. JAMA. 2001;286:2815.

19. Sambrook PN, Dequiker J, Rasp HH. Metabolic bone disease, Report of a WHO study group. Assessment of fracture risk and its application to screening for postmenopausal Osteoporosis. WHO Technical Report Series, Geneva;1994:5.

20. Gur A, Jale AS, Nas K, Cevik R. The relationship between educational level and bone mineral density in postmenopausal women, BMC Fam Pract. 2004;5:18.

21. Lau EMC, Tsai KS, Woo J, Chan NF, Leung PC, Lim $\mathrm{L}$, et al. Bone mineral density in Hong Kong and
Taiwan Chinese, women: a comparative study. HKMJ. 1995; 1:53-72.

22. Douchi T, Yamamoto S, Oki T, Maruta K, Kuwahata R, Nagata Y. Relationship between body fat distribution and bone mineral density in premenopausal Japanese women. Obstet Gynecol. 2000;95(5):722-5.

23. Enchev E, Botushanov N, Dzhambazova E. Bone mineral density in premenopausal and postmenopausal women between 50-55 and 50-57 years of age, Akush Ginekol (sofia). 2007;46(2):714.

24. Keramat A, Patwardhan B, Larijani B, Mithal A, Chakravarty D, Adib H, Khosravi A, et al. The assessment of osteoporosis risk factors in Iran women compared with Indian women, BMC Musculoskelet Disord. 2008;9:28. 